\title{
A STUDY ON FOREIGN INSTITUTIONAL INVESTMENT FLOWS AND STOCK INDEX
}

\author{
${ }^{1}$ N.Gopinathan, ${ }^{2}$ Dr. S. Sambasiva Rau \\ ${ }^{1}$ Research scholar, Sathyabama University, Chennai - 600119. \\ ${ }^{2}$ Professor, Sathyabama University, Chennai - 600119. \\ Email : 'gopi_nishnava@yahoo.com
}

\begin{abstract}
Flls are institutions established or incorporated outside India, which proposes to make investment in Indian securities. The Indian economic reforms have led to fast growth in economy, corporate restructuring and improved Forex reserve, making India an attractive destination for investment. Sensex is an "index" of BSE stocks. It gives an idea of the stocks market movement. The Sensex is an indicator of all the major companies of the BSE whereas Nifty is an indicator of all the major companies of the NSE. The present study makes an analyse of trading of FII and stock index during the period June 2000-March 2007 giving emphasis on quarterly data on Fll flows and corresponding stock indices such as Sensex and Nifty. Statistical tools like Regression Analysis, Correlation Analysis and Trend Analysis have been used in the study.
\end{abstract}

\section{Key words:}

\section{GLOBAL ECONOMIC SCENARIO}

India is a lower income country coming under the south Asian region, according to the classification made by the World Bank on the basis of Income and region. It is one of the fastest growing economies in the world. The rising service sector being boosted by the information technology has drawn the attention of the globe.

Presently Indian economy has become successful in keeping its external position very strong in the international market. Its rising infrastructure and cheaper manpower has attracted the foreign investors to make more investments.

The implication of global financial markets for India are analyzed in the light of the need for external capital in the form of NRI deposits and directs Foreign Investment. In order to facilitate the Indian Financial Institutions and business to globalise their activities more, the need for establishing an off banking and financial center is also emphasized. The setting up of such a center encourages a greater flow of foreign capital in to the country.

\section{EMERGING Vs DEVELOPED ECONOMIES}

An emerging market economy must have to weigh local political and social factors as its attempts to open up its economy to the world. The people of an emerging market, who before were protected from the outside world, can often be distrustful of foreign investment. Emerging economies may also often have to deal with issues of national pride because citizens may be opposed to having foreigners owning parts of the local economy.

Moreover, opening up an emerging economy means that it will also be exposed to not only new work ethics and standards but also cultures as well: indeed the introduction and impact of fast food and music videos to some local markets has been a by-product of foreign investment. Over the generations, this can change the very fabric of society and if population is not fully trusting of change, it may fight back hard to stop it.

\section{INDIAN ECONOMY-AN OVERVIEW}

As India prepares herself for becoming an economic superpower, it must expedite socio-economic reforms and take steps for overcoming institutional and infrastructure bottlenecks inherent in the system. Availability of both physical and social infrastructure is central to sustainable economic growth.

Since independence Indian economy has thrived hard for improving its pace of development. Notably in the past few years the cities in India have undergone tremendous infrastructure up gradation but the situation is not similar in most part of rural India. Currently Indian economy is facing these challenges:

Sustaining the growth momentum and achieving an annual average of $7-8 \%$ in the next five years.

$>$ Simplifying procedures and relaxing entry for barriers for business activities.

$>$ Checking the growth of population; India is the second highest populated country in the world after China.

> Boosting agricultural growth through diversification and development of agro processing.

$>$ Expanding industry fast, at least $10 \%$ per year.

$>$ Developing world-class infrastructure for sustaining growth in all the sectors of the economy.

$>$ Allowing foreign investment in more areas. 
$>$ Effecting fiscal consolidation and eliminating the revenue deficit through revenue enhancement and expenditure management.

$>$ Empowering the population through universal education and health care. India needs to improve its $\mathrm{HDI}$ rank, as at 127 it is way below many other developing countries performance.

\section{FOREIGN INSTITUTIONAL INVESTORS (FIIS)}

Foreign institutional investors (FIls) during last one decade have become an integral part of Indian equity markets. They have been an incredible source of money ever since. The influence of Flls is such that the market players anticipate their arrival with breathless anxiety. This reputation of the Flls is a well-earned status. The authority of these institutions is evident from the very fact that by the mere news of their arrival it is sufficient for the market to supplement itself with a double-digit growth. The era of Flls investments in India originated in 1993. Flls of different countries, mainly the US, started operating in India. The number of Flls in India has grown over the years to nearly 750 . The big names include Morgan Stanely, Templeton, Capital International, CDC, Warburg and JFAM. Flls own almost a third of the free-floating market available for investment in the country.

A FII may be institution established or incorporated outside India, which proposes to invest securities in India. A FII may be a company or other institution established abroad. AFII may be any of the following-

a. A company or an institution incorporated outside India as pension fund, Mutual fund or Investment trust.

b. An Asset management company, Nominee Company, Bank or Institutional portfolio manager incorporated outside India and proposing to invest in India for broad-based funds.

c. Foreign Trustee or power of Attorney holder proposing to invest in India for broad-based funds.

d. Foreign university funds, Endowments, Foundations or Charitable trusts or Charitable societies in existence for at least 5 years and that they are registered with a statutory in the country of their incorporation and it is legally permissible for them to invest in securities outside the country of their incorporation.

A portfolio manager or mutual fund doing business in India, approved by SEBI, who act as investment agent for a foreign party and who makes investment in securities on behalf of the foreign party out of funds brought from abroad shall also be deemed to be Fll.

\section{SENSEX AND NIFTY}

The Sensex is an "index". An index is basically an indicator. It gives a general idea about whether most of the stocks have gone up or most of the stocks have gone down. The Sensex is an indicator of all the major companies of the BSE.The Nifty is an indicator of all the major companies of the NSE.If the Sensex goes up, it means that the prices of the stocks of most of the major companies on the BSE have gone up. If Sensex goes down, this tells that the stock prices of most of the major stocks on the BSE have gone down.

Just like the Sensex represents the top stocks of the BSE, the Nifty represents the top stocks of the NSE. The BSE, is the Bombay Stock Exchange and the NSE, is the National Stock Exchange. The BSE is situated at Bombay and the NSE is situated at Delhi. These are the major Stock Exchanges in the country. There are other Stock Exchanges like the Calcutta Stock Exchange etc., but they are not as popular as the BSE and the NSE. Most of the stock trading in the country is done through the BSE \& the NSE.

\section{METHODOLOGY}

- Data: Secondary data are used for the study. The literature pertaining to Flls, Sensex and Nifty are collected from books, journals and newspapers. Access to the annual reports of RBI and the economic survey. For the purpose of the study, extensive use of the database like website of NSE, BSE and RBI are used.

- Data analysis: The data collected were put to statistical analysis in order to know whether or not the flow of Flls in the Indian stock market has significantly affected the SENSEX and NIFTY. For the purpose of study statistical tools like correlation analysis, regression analysis and trend analysis are used.

- Period of the study: For this purpose data are collected for the years from 2000 to March'2007.

The calculated mean value of Fll flows is 4071.21. The computed mean value of Nifty is 2253.33 . The relevant trend values are:

$X=2.6 Y-1823.49$ and

$Y=2.16 x-6572.97$.

The relevant 'r' score between FII flows and Nifty is 0.66 . This is depicted in Fig: 1 
Trend Analysis

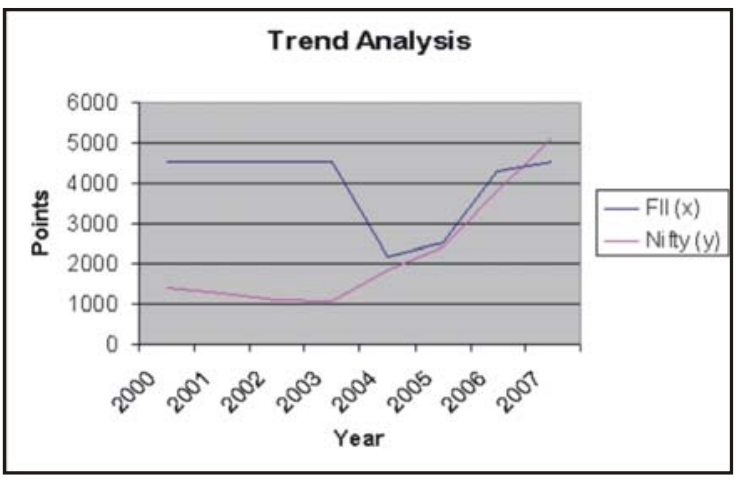

Fig. 1.

\section{ANALYSIS AND DISCUSSION IMPACT OF FII FLOWS ON NIFTY}

Table 1. Source SEBI

\begin{tabular}{|l|l||l|}
\hline Year & FII & Nifty \\
\hline 2000 & 4536.59 & 1400.79 \\
2001 & 4536.59 & 1263.3 \\
2002 & 4536.59 & 1119.35 \\
2003 & 4536.59 & 1088.15 \\
2004 & 2183.72 & 1829.96 \\
2005 & 2516.19 & 2418.7 \\
2006 & 4275.61 & 3777.81 \\
\hline 2007 & 4536.59 & 5130.23 \\
\hline & & \\
\hline
\end{tabular}

\section{Interpretation}

As revealed in fig 1 , it is observed that Fll flow is remained flat between the year 2000 and 2004, but Nifty shows a falling trend during that period. Its further revealed that steep fall in FII flows during the year 2004 to 2005 , but Nifty shows a increasing trend from 2004 to 2006. This shows clearly that Nifty was not affected by the impact of Fll's steep fall. However during the period between 2005 and 2007 we could see more FIl inflow.
IMPACT OF FII FLOWS AND SENSEX

Table 2. Source SEBI

\begin{tabular}{|l|l|l|}
\hline YEAR & FII & Sensex \\
\hline \hline 2000 & 4536.59 & 5781.37 \\
2001 & 4536.59 & 5781.37 \\
2002 & 4536.59 & 5781.37 \\
2003 & 4536.59 & 5781.37 \\
2004 & 2183.72 & 2779.65 \\
2005 & 2516.19 & 3795.96 \\
2006 & 4275.61 & 5270.76 \\
2007 & 4536.59 & 5781.37 \\
\hline \hline & 32659.71 & 40753.2 \\
\hline
\end{tabular}

The calculated mean value of Fll flows is 4071.21. The computed mean value of Sensex is 5094.15. The relevant trend values are: $X=1.48 y-3468.13$ and $Y=0.85 x-$ 1633.63. The relevant ' $r$ ' score between Fll flows and Sensex is 0.97 . This is depicted in Fig. 2.

\section{Trend Analysis}

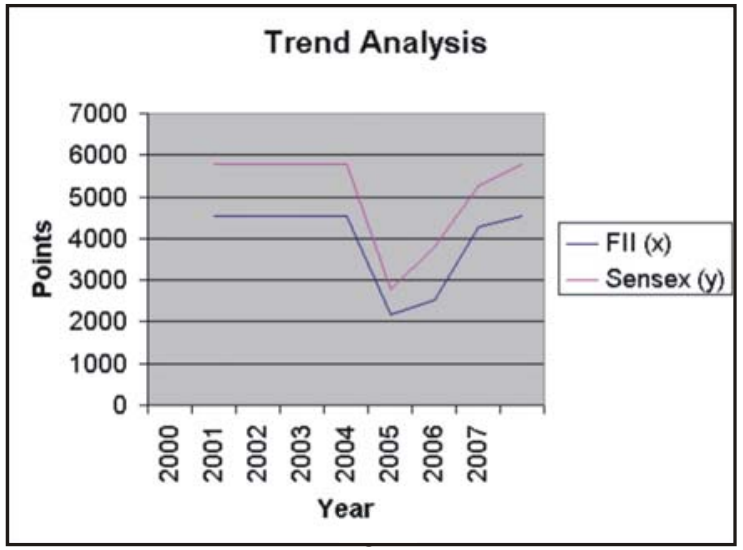

\section{Interpretation}

As revealed in fig 2, there seems to be positive correlation where the movement of FII inflows increases Sensex also increases. It is observed that both Fll flow and Sensex remained flat from the year 2000 to 2006 . It is revealed that steep fall in the FII inflow during the year 2004 to 2005 as resulted in corresponding steep fall in 
Sensex also. This clearly shows as to how Sensex is very much impacted by Fll flow. However during the year 2006 to 2007 we could see a perceptible recovery in the Sensex. This was mainly made by the huge FIl inflows.

\section{SUMMARY}

Comparison of FII with Nifty and FII with Sensex is done to know the relationship and to know the effect of Sensex and Nifty on account of FII flows. Fll flow is one the important source that directly influences the Nifty and Sensex and also the National economy.

\section{FINDINGS}

\section{FllVs Nifty}

It is observed that Fll flow is remained flat from the year 2000 to 2004, but Nifty shows a falling trend during that period. It is further revealed that steep fall in Fll flows during the year 2004 to 2005, but Nifty shows a increasing trend from 2004 to 2006. This shows clearly that Nifty was not affected by the impact of Fll's steep fall. However during 2005 to 2007 we could see more Fll inflow.

\section{FllVs Sensex}

It is observed that both FII flow and Sensex remained flat from the year 2000 to 2006 . It is revealed that steep fall in the Fll inflow during the

year 2004 to 2005 has resulted in corresponding steep fall in Sensex also. This clearly shows as to how Sensex is very much impacted by Fll flow. However during the year 2006 to 2007 we could see a perceptible recovery in the Sensex. This was mainly made by the huge FII inflows.

\section{CONCLUSION}

Based on the findings from the statistical analysis we can conclude that Fll flows greatly influence the performance of Nifty as well as Sensex.

\section{REFERENCES}

[1] Bandyopadhyay, Tamal.2003. Three myths about Flls. Business Standard, November 27.
[2] Balasubramanyam. V.N. And M.Salisu. 1996. Foreign Direct Investment and growth, Discussion paperNo 7 , Lancester University.

[3] Rajesh Chakarabarti. "FIl Flows to India: Nature and Causes"-AnArticle.

[4] Dr.S. Guruswamy, text book on Financial services.

[5] Indian Economic Survey-2006

[6] Nitin Mehrotra and Sudha Suswaram. An Article on "FIls and Indian Equity Markets".

[7] Shrawan Kumar Singh. An Article on "Foreign Portfolio Investment in India"- The Indian journal of commerce: December, 2004.

\section{WEBSITES}

1. www.rbi.org

2. www.sebi.org.in

3. www.nseindia.com

4. www.bseindia.com

5. search.ebscohost.com

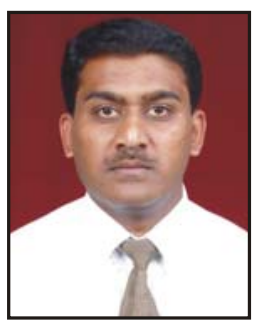

N.Gopinathan, Research ScholarSathyabama University, has 13 years of Academic experiences. He has organized several workshops and has presented several papers in National and International conferences. His research interest is Investment Market. 


\title{
APPLICATION OF FRACTIONAL STOCHASTIC PROGRAMMING IN BUS TRANSPORT COMPANY
}

\author{
S.Kala', M.Jeeva² \\ 'Department of Mathematics St.Peter's University, Chennai, India. \\ ${ }^{2}$ Department of Mathematics Ethiraj College for Women, Chennai, India. \\ Email : ${ }^{1 m v \_j e e v a @ y a h o o . c o m ~}$
}

\section{Abstract}

The aim of this paper is to maximize the ratio of profit per journey to total journey time of a bus transport company subject to a set of probabilistic and linear constraints using stochastic and fractional linear programming. We present the conversion of probabilistic constraints into deterministic constraints. Numerical examples are also illustrated.

Key words: Journey time, Probabilistic constraints, Deterministic constraints, Fractional programming, Stochastic programming.

\section{INTRODUCTION}

We consider a bus transport company with ' $\mathrm{k}$ ' buses which are flying from ' $m$ ' different sources called as depots say $D_{1}, D_{2}, \ldots, D_{m}$. Buses from one depot say $D_{i}$ fly to various other destinations $D_{j}$, where $i$ Aand $i=1,2, \ldots, m$.

We are interested to maximize the ratio of total profit per journey for all buses to the total journey time of all buses. Here the profit and journey time are assumed to be random in nature and constraints involved in this problem are assumed to be linear and probabilistic. Hence the problem under consideration is a linear fractional stochastic programming problem (LFSPP), where the parameters follow certain empirical distributions. In our case it is assumed to follow a normal distribution.

Section 2 deals with LFSPP models and also the conversion of probabilistic constraints into deterministic constraints [1-4]. Section 3 provides examples for LFSPP models. Section 4 gives the conclusion.

\section{Linear fractional stochastic programming models}

Our goal is to decide on the optimal number of buses to be departed from one source to various destinations with the objective of maximizing the ratio of total profit to the total journey time.

Let $x_{i j}$ be the number of buses flying from $i^{\text {th }}$ source $D_{i}$ to the $j^{\text {th }}$ destination $D_{j}$, where $i$. Let $T_{i j}$ be the journey time of a bus from $D_{i}$ to $D_{j}$ for $i$. Let $P_{i j}$ be the profit per bus per journey from $D_{i}$ to $D_{j}$ for $i$. It is clear that $x_{i i}=0, T_{i i}=0, P_{i i}=0$ for all $i=1,2,3 \ldots, m$. Let $x_{i}$ be the total number of buses flying from the source $D_{i}$ to various destinations and $y_{j}$ be the total number of buses arrived at the destination $D_{i}$ from various sources, $i, j=1,2, \ldots, m$.

As the aim of the bus transport company is to make maximum profit per journey, it is essential to fix a minimum profit per journey for each source depot. Let $\mathrm{a}_{\mathrm{i}}$ be the minimum profit from source depot $D_{i}, i=1,2, . ., m$. As the journey time cannot go on, it should be bounded and hence the journey time for each source depot is assumed to be less than or equal to some time limit say $b i, i=1,2, . ., m$.

The mathematical formation of LFSPP model is defined as follows:

Maximize the fractional objective function

$$
f(x)=\frac{S_{j=1}^{m} S_{\mathrm{i} 1 \mathrm{j}}^{m} P_{P_{\mathrm{il}} x_{\mathrm{il}}}}{S_{j=1}^{m} S_{\mathrm{i} 1 \mathrm{j}}^{m}}
$$

Subject to

$$
\left.\left.\left.\mathrm{P} \sum_{j \mathrm{j} j}^{m} \mathrm{P}_{i j} x_{i j}\right] a_{i},\right](]_{a_{i}}\right) . i \mathrm{ij} .2 .<<m_{<}<.
$$

$$
\left.\left.\mathrm{P}>\sum_{j \mathrm{lj}}^{m} \mathrm{~T}_{i j} x_{i j}\right] b_{i}, \underline{\mathrm{j}_{\mathrm{j}}}\right]_{\left.\beta_{i}\right) . i \mathrm{ij} .2 .<<m_{<}<}
$$

$$
\sum_{j 1 \mathrm{j}}^{m} x_{i j} \& x_{[} \quad . j 1 \mathrm{j} .2 .<<<\pi k
$$

$$
\sum_{i_{1 \mathrm{j}}}^{m} x_{i j} \& y_{[} \quad . j 1 \mathrm{j} .2 .<<<\pi k
$$

$\sum_{i 1 \mathrm{j}}^{m} x_{i} 1 k \sim \sum_{j 1 \mathrm{j}}^{m} y_{i} 1 k$ 
$\sum_{j_{1 \mathrm{j}}}^{m} \sum_{i_{1 \mathrm{j}}}^{m} x_{i j} \quad 1 k, \forall_{i}, j \mathrm{j} .2 .<<m_{<}<$.

$x_{i i} 1 \cdot P_{i i} 1 \cdot T_{i i} 1, \mathrm{~V}_{i 1} \mathrm{j} .2 .<<m_{<}<$.

and $\left.x_{i j}\right]$. $\forall i . j 1 \mathrm{j} .2 .<<m_{<}<$.

Where $\alpha_{1}, \alpha_{2}, \ldots, \alpha_{m}$ and $\beta_{1}, \beta_{2}, \ldots, \beta_{m}$ are the level of significances, $\left(1-\alpha_{i}\right)$ and $\left(1-\beta_{i}\right), i=1,2, \ldots, m,\left(0 \leqslant \alpha_{1}\right.$, $\beta_{\mathrm{i}}$ \&) are the least probabilities with which the constraints (2.1) and (2.2) are satisfied.

Conversion of probabilistic constraints into deterministic constraints.

Model - I

Let $P_{i i}$ be the independent random variable denoting the profit function associated with the source $D_{i}$. Let $T_{i j}$ be the independent random variable denoting the journey time associated with the source $D_{i}$. Under this model, we assume $a_{i}$ and $b_{i}$ be the fixed constants. We also assume that $P_{i j}$ and $T_{i j}$ follow normal distribution with respective finite means and variances.

Let $\bar{P}_{i \mathrm{ij}}$ and $S_{\text {ii }}^{2}$ be the estimated mean and variance of $\mathrm{P}_{\mathrm{ij}}$ and $\bar{T}_{\mathrm{ij}}$ and $S_{\mathrm{ij}}^{2}$ be the estimated mean and variance of $T_{\mathrm{ij}}$ obtained by Maximum Likelihood Method.

Let

$$
\begin{gathered}
l_{i}=\sum_{j=1}^{m} P_{i j} x_{i j} \\
E\left(l_{i}\right)=\sum_{j=1}^{m} \overline{P_{i j}} x_{i j} \\
\operatorname{var}\left(l_{i}\right)=\sum_{j=1}^{m} S_{P i}^{2} x_{i j}^{2} \quad \forall i=1,2, \ldots ., m .
\end{gathered}
$$

The $i^{\text {th }}$ probabilistic constraint of (2.1) is given by

$$
\begin{aligned}
& P\left[l_{i} \geq a_{i}\right] \geq\left(1-\alpha_{i}\right) \\
& \text { or } \\
& P\left[Z_{i} \geq z_{i}\right] \geq\left(1-\alpha_{i}\right) \\
& \text { where, } Z_{i}=\frac{l_{i}-E\left(l_{i}\right)}{\sqrt{\operatorname{var}\left(l_{i}\right)}} \quad \& \quad z_{i}=\frac{a_{i}-E\left(l_{i}\right)}{\sqrt{\operatorname{var}\left(l_{i}\right)}}
\end{aligned}
$$

Here $Z_{i}$ is the standard normal by Central limit theorem.

From (2.9)

$$
1-P\left[Z_{i} \leq z_{i}\right] \geq\left(1-\alpha_{i}\right)
$$

which implies $P\left[Z_{i} \leq z_{i}\right] \leq \alpha_{i}$

$$
\text { Thus } \quad \Phi\left(z_{i}\right) \leq \Phi\left(K_{a i}\right)
$$

Where is the cumulative distribution function of the standard normal variable $Z_{i} 0 \mathrm{~N}(0,1)$ and $\mathrm{K}_{\mathrm{ai}}$ is the table value of normal distribution for the level of significance $a_{i}$. Since $\Phi$ is a non-decreasing continuous function, (2.10) implies $z_{i} K_{i}$.

Thus,

$$
E\left(l_{i}\right)+K_{a i} \sqrt{\operatorname{var}\left(l_{i}\right)} \geq a_{i}
$$

This implies

$$
\text { Hence, } \begin{array}{r}
\sum_{j=1}^{m} \overline{P_{j}} x_{i j}+K_{a i}\left(\sum_{j=1}^{n} S_{F_{j}}^{2} x_{i}^{2}\right)^{\frac{1}{2}}-a_{i} \geq 0(2.12 \\
\forall i=1,2, \ldots \ldots \ldots, m .
\end{array}
$$

Let

$$
\begin{aligned}
& q_{i}=\sum_{j=1}^{m} T_{i j} x_{i j} \\
& E\left(q_{i}\right)=\sum_{j=1}^{m} \overline{T_{i j}} x_{i j} \\
& \operatorname{var}\left(q_{i}\right)=\sum_{j=1}^{m} S_{T_{i j}}^{2} x_{i j}^{2}
\end{aligned}
$$

The $i^{\text {th }}$ probabilistic constraint of $(2.2)$ is

$$
\begin{aligned}
& P\left[q_{i} \leq b_{i}\right] \geq\left(1-\beta_{i}\right) \\
& \text { or } \\
& P\left[Z_{i}^{\prime} \leq z_{i}^{\prime}\right] \geq\left(1-\beta_{i}\right) \\
& \text { where, } \quad Z_{i}^{\prime}=\frac{q_{i}-E\left(q_{i}\right)}{\sqrt{\operatorname{var}\left(q_{i}\right)}} \quad \& \quad z_{i}^{\prime}=\frac{b_{i}-E\left(q_{i}\right)}{\sqrt{\operatorname{var}\left(q_{i}\right)}}
\end{aligned}
$$

Here $\mathrm{i} Z$ is the standard normal variable by Central limit theorem.

From (2.13), $\Phi\left(z_{i}^{\prime}\right) \geq \Phi\left(K_{\left(1-A_{i}\right)}\right)$ 